\title{
Remoção de Contaminantes em Meio Aquoso Usando Carvão Ativado. InfluênCIa do Adsorvito, Força lónICA e Química Superficial
}

\author{
Nelson Nunes e Angela Martins* \\ Área Departamental de Engenharia Química, Instituto Superior de Engenharia de Lisboa (ISEL), Lisboa \\ CQB, Universidade de Lisboa, Faculdade de Ciências, Lisboa \\ amartins@deq.isel.ipl.pt
}

\begin{abstract}
Removal of Contaminants in Aqueous Medium Using Activated Carbon. The Effect of Adsorbate, Ionic Strength and Surface Chemistry - In the presented work we intend to use simple laboratory experiments to illustrate a water treatment applying commercial activated carbon as adsorbent agent. The removal of an industrial textile dye, Mordent Blue-9 and caffeine, considered a surface water pollution marker, will be tested. The influence of the activated carbon surface chemistry will also be explored, illustrating the effect of interactions between the carbon surface and the adsorbates molecules. Moreover, the influence of solution ionic strength will be also tested, simulating different water hardnesses.
\end{abstract}

presente trabalho pretende ilustrar através de experiências laboratoriais simples a aplicação de um carvão ativado comercial como agente de tratamento de águas através da sua utilização na remoção de dois diferentes contaminantes, o Azul Mordente-9, um corante têxtil industrial, e a cafeína, considerada como um marcador de poluição de águas superficiais.

Pretende-se ainda explorar a influência da química superficial do carvão ativado, ilustrando assim distintas interações entre a superfície do carvão e as moléculas de adsorvato. Um outro objetivo é mostrar o efeito da força iónica da solução no processo de adsorção, simulando desta forma águas de diferentes durezas.

\section{INTRODUÇÃO}

A adsorção define-se como a interação de moléculas com a superfície de um sólido. Trata-se de um conceito chave que se encontra na base de diversas aplicações como a catálise heterogénea, a descontaminação de águas e efluentes gasosos, a análise cromatográfica, entre outras. A interação entre moléculas adsorvidas (adsorvato) e a superfície do sólido (adsorvente) pode ser tipificada em duas categorias: a fisissorção, quando as moléculas adsorvidas estabelecem com o adsorvente ligações fracas do tipo electrostático e quimissorção quando as moléculas se ligam fortemente à superfície do material, podendo até ocorrer transformações químicas, o que está na base, por exemplo, da catálise heterogénea. Os fundamentos teóricos que explicam o processo de adsorção bem como as suas aplicações assumem um papel relevante nos programas de Química-Física das Licenciaturas em Química, Engenharia Química e outros cursos relacionados, encontrando-se o capítulo de adsorção na maior parte dos livros de estudo recomendados $[1,2]$ bem como num número significativo de artigos em revistas dedicadas ao ensino da Química, por exemplo o "Journal of Chemical Education” [3-6] ou em manuais de laboratório [7-8].

Existe uma grande variedade de materiais adsorventes, desde materiais naturais como carvões, carvões ativados e argilas, até materiais sintéticos com aplicações muito específicas como os zeólitos. No entanto, os carvões ativados são os adsorventes por excelência, sendo obtidos a partir da queima controlada de madeira, a uma temperatura entre 800 e $1000^{\circ} \mathrm{C}$ na presença de baixo teor de oxigénio, a fim de evitar a queima total do material e promover o desenvolvimento de porosidade. Obtêm-se assim materiais com uma capacidade de retenção de cerca de 100 vezes superior ao carvão comum, com excelente poder de clarificação, desodorização e purificação de efluentes, em particular na remoção de corantes, metabolitos de medicamentos, etc. No entanto, os elevados custos da matéria-prima têm levado à procura de fontes alternativas para obtenção de carvões ativados a partir de desperdícios de baixo custo, como por exemplo casca de coco, caroços de azeitona, serradura, etc. [9-11].

Os efluentes da indústria têxtil encontram-se entre os principais poluentes do meio aquático devido à presença de corantes têxteis, sendo um deles o corante Azul Mordente-9 (AM-9), usado no tingimento de lãs e sedas. Este corante pertence à categoria dos corantes "azo”, assim chamados devido à presença de uma ou mais ligações $(-\mathrm{N}=\mathrm{N}-)$ bem como de anéis aromáticos. A estrutura molecular do corante AM-9 encontra-se representada na Figura 1(A). Os corantes azo representam cerca de $60-70 \%$ dos corantes usados na indústria química e são conhecidos pela sua toxicidade.

A cafeína é um alcaloide presente em numerosas bebidas e em alguns produtos alimentares, encontrando-se a sua estrutura molecular representada na Figura 1(B). Além de ser uma substância estimulante é também um diurético, para além de acentuar a ação de alguns medicamentos [12]. Devido ao seu elevado consumo e baixa degradação a cafeína é um dos compostos mais facilmente detetados em afluentes e efluentes de estações de tratamento de esgotos e vários estudos reportam a sua presença em águas superficiais (rios, lagos, lagoas). Devido à sua origem antropogénica, é 
considerado por vários autores como um possível marcador químico para a poluição das águas superficiais proveniente de águas residuais domésticas [13,14].<smiles>O=[N+]([O-])OS(=O)(=O)c1cc(Cl)cc(N=Nc2ccc3c(S(=O)(=O)O[Na])cccc3c2O)c1O</smiles>

(A)<smiles>Cn1c(=O)c2c(ncn2C)n(C)c1=O</smiles>

Figura 1 - Estrutura molecular dos adsorvatos utlizados: (A) Azul Mordente-9 e (B) cafeína

A capacidade de retenção de moléculas num carvão ativado é determinada não apenas pela sua estrutura porosa mas também pela sua composição química. Os grupos oxigenados superficiais (GOS) são formados durante o processo de ativação do carvão, através da interação com o oxigénio. Podem também resultar de tratamentos posteriores, por interação com agentes oxidantes gasosos como ozono, óxido nitroso, entre outros, ou líquidos como ácido nítrico, peróxido de hidrogénio, etc [15].

Existem vários tipos de grupos oxigenados superficiais, tal como se pode observar na Figura 2. A natureza destes grupos é responsável pelas propriedades básicas ou ácidas da superfície do carvão, o que do ponto de vista químico, é o parâmetro chave para a interação eficaz entre o adsorvente e as moléculas de adsorvato. aquático. Pretende-se que os estudantes façam a determinação experimental de isotérmicas de adsorção bem como a aplicação dos respetivos modelos, como Langmuir ou BET, que permitem estimar a capacidade de adsorção dos materiais. O tratamento de resultados poderá ser mais simplificado recorrendo a regressões lineares. Este trabalho pretende também explorar o efeito da química superficial do carvão através da realização de tratamentos oxidativos nas amostras, analisando assim as interações dos grupos oxidativos superficiais com as moléculas do adsorvente. Por outro lado, será modificada a força iónica nas soluções de corante, simulando diferentes durezas da água.

\section{PROCEDIMENTO EXPERIMENTAL}

\section{REAGENTES}

Corante têxtil Azul Mordente-9 $\left(\mathrm{C}_{16} \mathrm{H}_{9} \mathrm{ClN}_{2} \mathrm{Na}_{2} \mathrm{O}_{8} \mathrm{~S}_{2}\right.$, 502,81 g/mol, Sigma-Aldrich)

Cafeína $\left(\mathrm{C}_{8} \mathrm{H}_{10} \mathrm{~N}_{4} \mathrm{O}_{2}, 194,19 \mathrm{~g} / \mathrm{mol}\right)$ Sigma-Aldrich, 99\%

$\mathrm{CaCl}_{2} \cdot 2 \mathrm{H}_{2} \mathrm{O}$ (Sigma-Aldrich, $99 \%$ ) e $\mathrm{MgCl}_{2} \cdot 6 \mathrm{H}_{2} \mathrm{O}$ (Aldrich, 99,95\%)

Carvão ativado Panreac (Lot. 0000115091)

Solução $\mathrm{HNO}_{3}$ (Sigma-Aldrich, ACS, 70\%)

\section{EQUIPAMENTOS}

Aparelho de pH (Crison GLP22); Banho termostático (Julabo MP); Agitador multi-posições (Selecta Multimatic

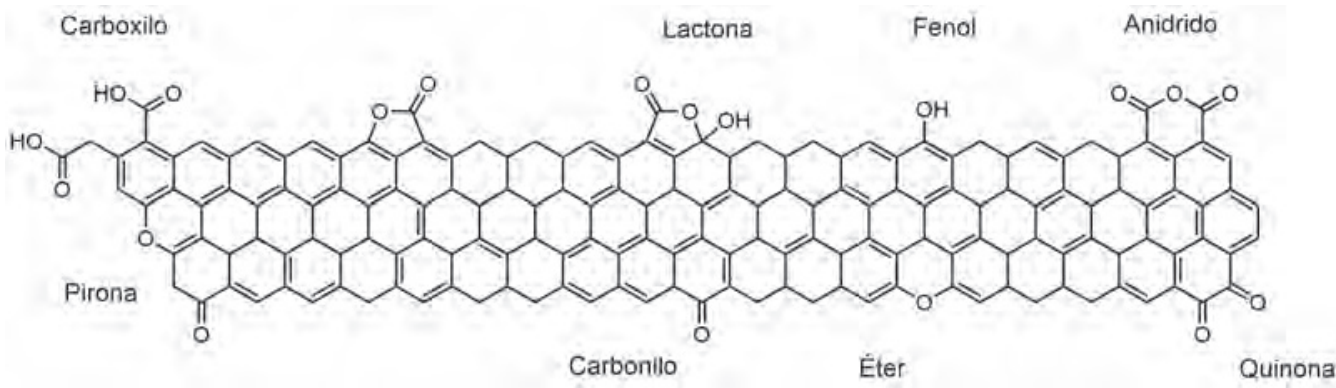

Figura 2 - Tipos de grupos oxigenados superficiais (GOS) presentes em amostras de carvão ativado.

A quantidade e tipo de GOS presente na superfície do carvão é também responsável pela presença de cargas positivas e negativas que se geram quando o carvão é colocado numa solução aquosa, dependendo do pH. Para um pH específico, a carga global da superfície será nula, sendo assim designada por ponto de carga zero, $\mathrm{pH}_{\mathrm{pzc}}$. Assim, quando $\mathrm{pH}>\mathrm{pH}_{\mathrm{PZC}}$ a superfície do carvão irá atrair catiões da solução onde se encontra imerso, por outro lado, quando pH < $\mathrm{pH}_{\mathrm{PZC}}$ a superfície irá atrair os aniões.

\section{DESCRIÇÃO GLOBAL DA EXPERIÊNCIA}

Este trabalho, dirigido a alunos de Licenciatura em Química, Engenharia Química ou áreas afins, pretende ilustrar conceitos básicos de adsorção, usando amostras de carvão ativado comerciais na remoção de contaminantes do meio
9-S); Centrífuga Hermle Z206A. Espectrofotómetro de UV-Visível de feixe duplo (Jasco V530); Placa de aquecimento (IKA CMagHS7).

\section{PREPARAÇÃO dAS SOLUÇõES}

A solução concentrada de AM-9 (200 mg/L) foi preparada dissolvendo o sólido em água desionizada e foi usada como solução stock, AM9.

A amostra de água "dura sintética” foi preparada usando $\mathrm{CaCl}_{2} \cdot 2 \mathrm{H}_{2} \mathrm{O}$ e $\mathrm{MgCl}_{2} \cdot 6 \mathrm{H}_{2} \mathrm{O}$ por forma a obter um nível de dureza de $200 \mathrm{mg} / \mathrm{L}$ equivalentes de $\mathrm{CaCO}_{3}$.

Esta solução foi depois utilizada para dissolver o corante AM-9 e obter uma solução stock adicional, AM9-200. 
Após as 2 h de tempo de contacto o carvão e o corante/ cafeína as amostras de carvão são separadas da solução por

Uma das amostras de carvão comercial foi usada sem qualquer tratamento adicional. A outra amostra do mesmo carvão foi sujeita a um tratamento oxidativo tendo por objetivo alterar a quantidade de grupos oxigenados superficiais (GOS). Neste tratamento, 20 mL de solução de $\mathrm{HNO}_{3}$ 4,6 $\mathrm{M}$ foi adicionada a $2 \mathrm{~g}$ da amostra de carvão ativado. A suspensão foi aquecida a $60^{\circ} \mathrm{C}$ numa placa de aquecimento até se obter uma pasta, por evaporação da água. A pasta foi depois filtrada usando papel de filtro e lavada diversas vezes até o pH do filtrado ser idêntico ao da água desionizada, deixando-se a secar à temperatura ambiente por 24 h. $\mathrm{O}$ tempo de preparação das amostras para utilização em aulas poderá ser encurtado se as soluções stock bem como o tratamento oxidativo dos carvões for previamente executado.

\section{ENSAIOS DE ADSORÇÃO}

De acordo com um plano de trabalho previamente estabelecido cada grupo de alunos poderá estudar um par adsorvente/adsorvato diferente, começando por preparar entre seis a oito soluções diluídas num intervalo de concentrações entre 20 e 120 mg/L a partir da solução stock correspondente. Em seguida dever-se-á proceder à pesagem rigorosa de seis a oito amostras de $10 \mathrm{mg}$ de carvão ativado, que serão colocados em tubos de centrífuga com cerca de $100 \mathrm{~mL}$ de capacidade. A cada tubo, devidamente identificado, deverá ser adicionado $80 \mathrm{~mL}$ das soluções diluídas previamente preparadas. Após colocado um pequeno agitador magnético os tubos são depois tapados e imersos num banho termoestático a $30^{\circ} \mathrm{C}$. O banho deverá ser colocado sobre um agitador, preferencialmente com multi-posições, para assegurar a correta homogeneização de todas as suspensões em simultâneo. A Figura 3 exemplifica a montagem de termoestatização e homogeneização usada neste trabalho.

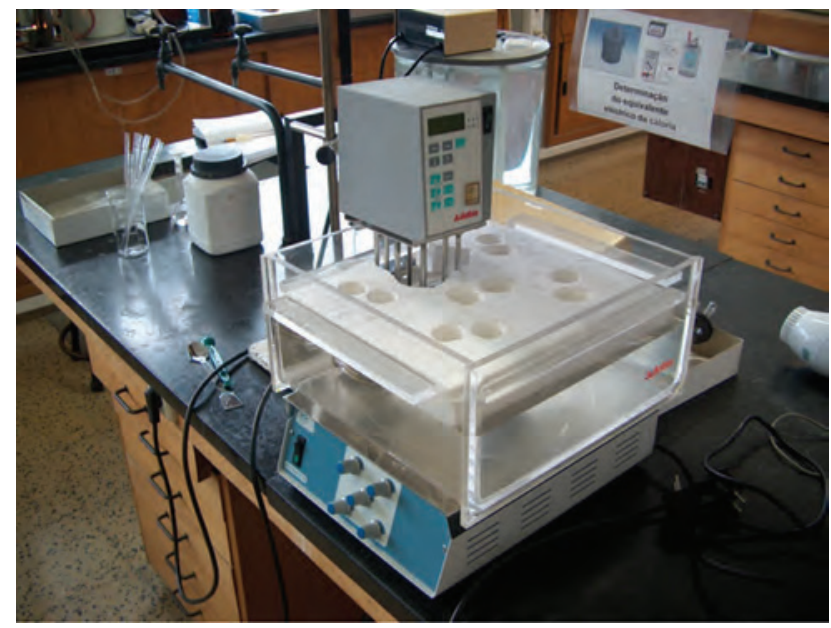

Figura 3 - Montagem de termoestatização e homogeneização dos ensaios de adsorção

O tempo necessário para atingir o equilíbrio adsorção/desadsorção, é de cerca de 2 h. Durante este período os estudantes podem realizar outras tarefas, nomeadamente: (i) realização da reta de calibração com as soluções diluídas (ii) preparação das amostras de carvão para determinação do $\mathrm{pH}_{\mathrm{pzc}}$. centrifugação ou caso não se disponha deste equipamento por filtração. São depois retiradas alíquotas de cada solução para medir as aborvâncias no comprimento de onda máximo. Cada ponto experimental resultará de pelo menos, três alíquotas/varrimentos individuais assegurando um desvio nas leituras de absorvância inferior a 5\%.

\section{- Construção da reta de calibração}

Na construção da curva de calibração é realizado o varrimento das soluções na gama de comprimentos de onda correspondentes às bandas de absorção características dos adsorvatos. O espectrofotómetro de duplo feixe utiliza na célula de referência água desionizada, solvente usado na preparação de todas as soluções.

No caso da cafeína o intervalo de varrimento é entre 200 e $400 \mathrm{~nm}$, na região de radiação ultravioleta, podendo ser utilizado o comprimento de onda de $273 \mathrm{~nm}$. No caso deste adsorvato, poderá ser necessário utilizar células de quartzo de menor percurso ótico (2 mm) para garantir a concordância com a lei de Lambert-Beer no intervalo de concentrações em estudo.

No caso do corante AM-9 o varrimento é entre 400 e 600 $\mathrm{nm}$, na região do visível, podendo ser escolhida a banda com o máximo de absorvância com um comprimento de onda de $520 \mathrm{~nm}$. No caso do corante esta gama de concentração permite utilizar células com $1 \mathrm{~cm}$ de percurso ótico.

\section{- Determinação do ponto de carga zero, $\mathrm{pH}_{\mathrm{pzc}}$}

Na medição dos pontos de carga zero (point of zero charge, $\mathrm{pH}_{\mathrm{pzc}}$ ) são adicionados $20 \mathrm{~mL}$ de água desionizada a $1 \mathrm{~g}$ da amostra de carvão (esta água deverá ser previamente fervida durante cerca de 1 h para remover o dióxido de carbono e depois deixada arrefecer à temperatura ambiente). A mistura pode ser deixada a agitar durante a atividade experimental e no final cada grupo pode realizar a medida de $\mathrm{pH}$.

Mais detalhes experimentais podem ser consultados na referência [16].

\section{RISCOS E SEGURANÇA}

O reagente $\mathrm{HNO}_{3}$ deverá ser manipulado com cuidado uma vez que é altamente corrosivo. O tratamento oxidativo deverá ser realizado preferencialmente numa hotte, uma vez que envolve a manipulação de soluções concentradas à temperatura de $60{ }^{\circ} \mathrm{C}$.

Dado que a experiência envolve a manipulação de pós muito finos (carvão ativado) ou tóxicos (corante AM-9, cafeína) os estudantes deverão utilizar equipamento individual de segurança como máscara para pós, óculos e luvas. 


\section{TRATAMENTO DE RESULTADOS}

As concentrações de adsorvato presentes em solução foram calculadas usando a lei de Lambert-Beer, que relaciona as absorvâncias medidas $(A)$ com a concentração das soluções $(C)$ e a absortividade molar $(\varepsilon)$. A relação linear é válida para a gama de concentrações estudadas (20 -120 $\mathrm{mg} / \mathrm{L}$ ) e para o percurso ótico (l) utilizado ( $1 \mathrm{~cm}$ no caso do AM-9 e 0,2 cm no caso da cafeína)

$$
A=\varepsilon . I . C
$$

As isotérmicas de adsorção foram obtidas conforme o procedimento acima descrito. Após 2 horas de contacto entre as soluções de adsorvato e as amostras de carvão, o equilíbrio entre as duas fases é atingido:

\section{Carvão + Adsorvato $\rightleftharpoons$ Adsorvato-carvão}

Uma vez que os valores experimentais obtidos através das medidas de absorvância permitem apenas determinar a concentração de adsorvato presente em solução, a quantidade de adsorvida na superfície do carvão ativado, $q_{e}$, expressa em mg de adsorvato por grama de carvão (mg/g) pode ser calculada usando a relação abaixo:

$q_{e}=\frac{C_{0}-C_{e}}{W} \cdot V$

onde $C_{0}$ - $C_{\mathrm{e}}$, é a diferença entre a concentração inicial e de equilíbrio do adsorvato em solução (mg/L) respetivamente, $W$ é a massa de carvão ativado (mg) e $V$ é o volume de solução em contacto com o carvão ativado (L).

A relação entre a quantidade adsorvida no carvão e a concentração de equilíbrio do adsorvato em solução pode ser descrita pela equação da isotérmica de Langmuir.

$$
q_{e}=\frac{q_{m} \cdot K_{L} \cdot C_{e}}{1+K_{L} \cdot C_{e}}
$$

onde $q_{\mathrm{m}}$ é a capacidade de adsorção (mg/g), $K_{L}$ é a constante de Langmuir (L/mg), que pode ser relacionada com a afinidade entre adsorvente e adsorvato. Os parâmetros $q_{\mathrm{m}}$ e $K_{L}$ são característicos de cada sistema adsorvente/adsorvato e podem ser determinados através da linearização da Eq. 3:

$$
\frac{C_{e}}{q_{e}}=\frac{1}{q_{m} \cdot K_{L}}+\frac{C_{e}}{q_{m}}
$$

A operação de transformar um gráfico hiperbólico (Eq. 3) num gráfico linear (Eq. 4.) é um procedimento realizado habitualmente noutras áreas de ciência. Representando $C_{\mathrm{e}} / q_{\mathrm{e}} \mathrm{em}$ função de $C_{\mathrm{e}}$, obtém-se uma linha reta (se o sistema adsorvente/adsorvato obedecer ao comportamento previsto pela equação de Langmuir), permitindo obter os valores de $K_{L} \mathrm{e}$ $q_{\mathrm{m}}$ a partir do declive e ordenada na origem, respetivamente.

\section{Resultados E DISCUSSÃO}

A capacidade de adsorção de materiais porosos depende fortemente das suas propriedades texturais. A Tabela 1 apresenta os parâmetros texturais do carvão ativado da marca comercial Panreac que foi usado neste estudo: volume microporoso, $\mathrm{V}_{\text {micro }}$ (correspondente a canais com aberturas de diâmetro inferior a $2 \mathrm{~nm}$ ), volume mesoporoso $\mathrm{V}_{\text {meso }}$ (diz respeito a canais com aberturas com diâmetro compreendido entre 2 e $50 \mathrm{~nm}$ ) e área superficial externa, $A_{\text {ext }}$. Os parâmeros texturais foram determinados a partir dos dados de isotérmicas de adsorção de $\mathrm{N}_{2}$ a $-196{ }^{\circ} \mathrm{C}$ obtidos num equipamento automático (ASAP 2010 da Micromeritics) e foram realizados no Laboratório de Adsorção - CQB/ FCUL. As informações detalhadas relativas à determinação dos parâmetros texturais encontram-se na ref. [17]. A caracterização textural da amostra de carvão pelos estudantes está fora do âmbito deste estudo. No caso de amostras comerciais estas características são geralmente fornecidas pelo fabricantes, podendo também encontrar-se alguns dados na bibliografia.

Tabela 1 - Parâmetros texturais do carvão ativado utilizado

\begin{tabular}{cccc}
\hline $\begin{array}{c}\text { Amostra de } \\
\text { carvão }\end{array}$ & $\begin{array}{c}\mathrm{V}_{\text {micro. }} \\
\left(\mathrm{cm}^{3} / \mathrm{g}\right)\end{array}$ & $\begin{array}{c}\mathrm{V}_{\text {meso. }} \\
\left(\mathrm{cm}^{3} / \mathrm{g}\right)\end{array}$ & $\begin{array}{c}\mathrm{A}_{\text {ext. }} \\
\left(\mathrm{m}^{2} / \mathrm{g}\right)\end{array}$ \\
\hline Panreac & 0,19 & 0,35 & 296 \\
\hline
\end{tabular}

Os valores de $\mathrm{pH}_{\mathrm{pzc}}$ relativos à amostra comercial e após o tratamento oxidativo, para a qual foi adotada a terminação “-Ox”, encontram-se na Tabela 2. O carvão comercial apresenta um valor de $\mathrm{pH}_{\mathrm{pzc}}$ perto da neutralidade, o que é comum para a maioria dos carvões ativados comerciais. Após o tratamento oxidativo com $\mathrm{HNO}_{3}$ a amostra Panreac-Ox revela um valor de $\mathrm{pH}_{\mathrm{pzc}}$ mais baixo o que indica uma maior concentração de GOS. Caso se pretenda um estudo mais aprofundado do efeito da química superficial do carvão podem ser realizados tratamentos oxidativos usando soluções de $\mathrm{HNO}_{3}$ ou $\mathrm{H}_{2} \mathrm{O}_{2}$ numa ampla gama de concentração, o que se irá traduzir numa maior variação de valores de $\mathrm{pH}_{\mathrm{pzc}}$. Em alternativa, as amostras já tratadas podem ser fornecidas aos estudantes.

A Figura 4 mostra as isotérmicas de adsorção do carvão comercial Panreac na presença dos dois adsorvatos, o corante AM-9 e a cafeína.

Comparando os dois adsorvatos, é notório que no caso do corante AM-9 a quantidade adsorvida, $q_{e}$, a baixas concentrações é maior o que reflete a maior interação entre o carvão e a molécula de AM-9, devido ao caráter iónico da molécula, o que leva a atingir valores próximos da capacidade máxima de adsorção do carvão a concentrações mais baixas.

Na Figura 5 mostra-se o efeito da força iónica e do tratamento oxidativo nas isotérmicas de adsorção do carvão Panreac usando o corante AM-9 como adsorvato. 


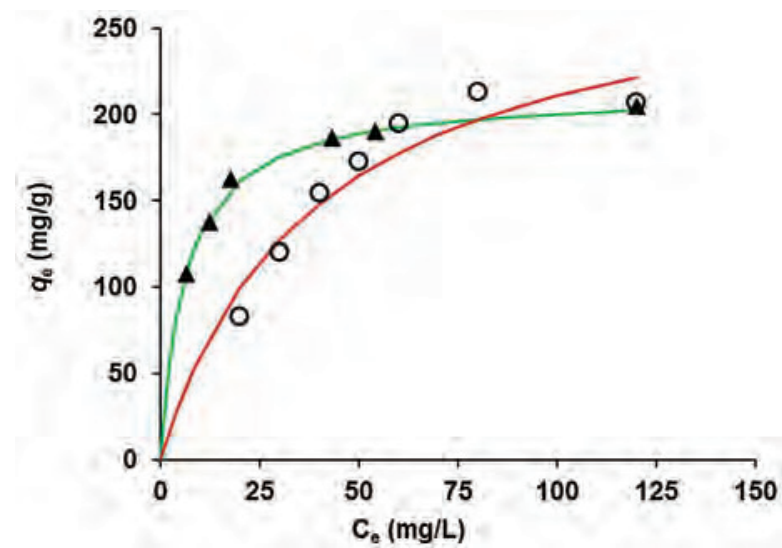

Figura 4 - Isotérmicas de adsorção dos adsorvatos AM-9 ( $\boldsymbol{\Delta}$ ) e cafeína (O), no carvão Panreac. As curvas a cores resultam da aplicação do modelo de isotérmica Langmuir.

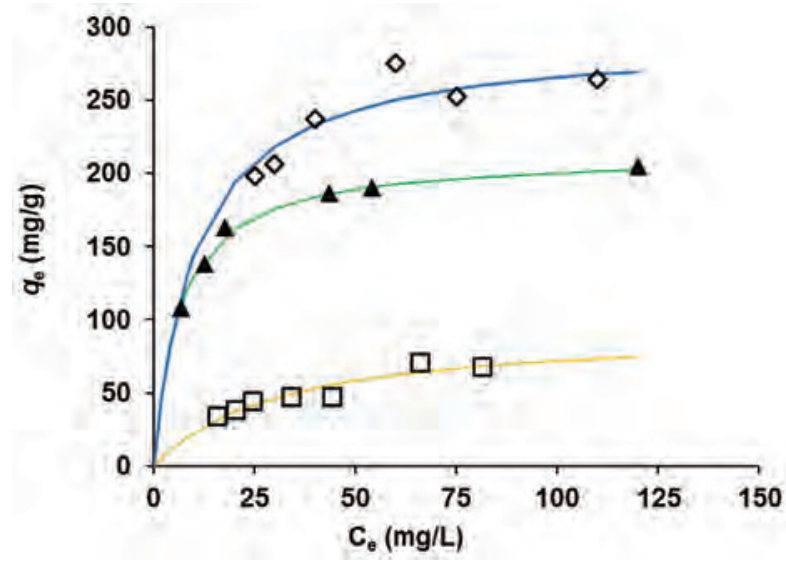

Figura 5 - Isotérmicas de adsorção do corante AM-9 no carvão Panreac: de partida ( $\mathbf{\Delta}$ ); na solução de dureza $200 \mathrm{mg} / \mathrm{L}$, Panreac-200 ( $\diamond$ ); com o carvão sujeito a tratamento oxidativo, Panreac-Ox ( $\square$ ). As curvas a cores resultam da aplicação do modelo de isotérmica Langmuir

A remoção do corante pelo carvão na presença de água de dureza elevada (Panreac-200) é superior em toda a gama de concentração de corante mostrando assim que a dureza da água é um parâmetro que influencia positivamente a interação com a superfície do carvão. Por outro lado a amostra sujeita a tratamento oxidativo (Panreac-Ox) mostra uma interação mais fraca com o corante o que se traduz numa menor capacidade de retenção do contaminante em toda a gama de concentração estudada.

A Figura 6 mostra a aplicação da equação de Langmuir na forma linearizada (Eq. 4) aos resultados experimentais obtidos nos vários ensaios. As equações apresentadas foram

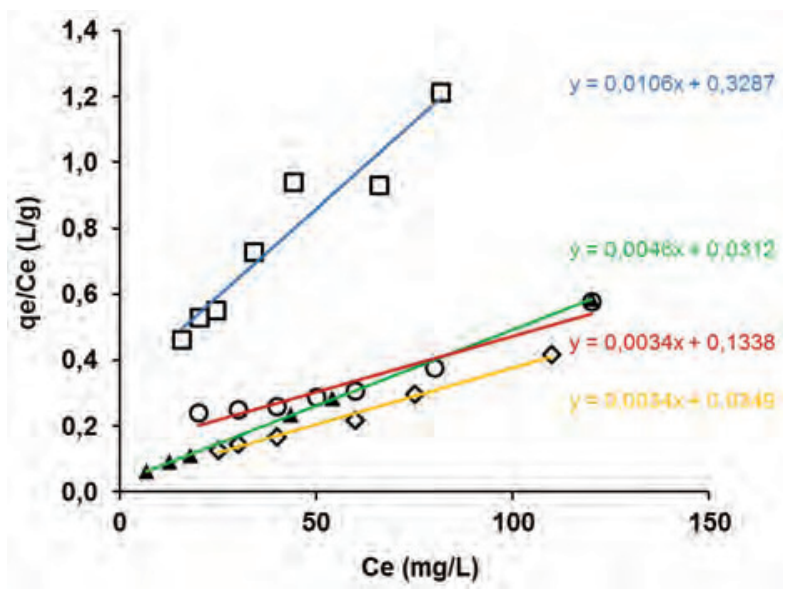

Figura 6 - Aplicação da isotérmica de Langmuir (forma linearizada) aos pontos experimentais nos diferentes ensaios: cafeína (O), AM-9 ( $\mathbf{\Delta})$, Panreac-200 ( | | ) e Panreac-Ox ( | | )

obtidas a partir de regressões lineares e os respetivos coeficientes de determinação $\left(R^{2}\right)$, bem como outros parâmetros estatísticos relevantes podem ser facilmente obtidos pelos estudantes usando a ferramenta de cálculo Microsoft Excel ${ }^{\circledR}$ ou outro software de estatística.

Na Tabela 2 encontram-se os parâmetros $K_{L}$ e $q_{m}$, calculados a partir da forma linearizada da equação de Langmuir (Eq.4) bem como os parâmetros estatísticos: coeficiente de determinação $\left(R^{2}\right)$; desvio padrão do ajuste $\left(s d_{f i t}\right)$ e o parâmetro de Fisher $(F)$. Os vários parâmetros estatísticos calculados mostram um bom ajuste entre os dados experimentais obtidos e a equação de Langmuir na forma linearizada, o que significa que este modelo de adsorção pode ser aplicado a estes sistemas adsorvente/adsorvatos.

Fazendo uma análise comparativa dos dois substratos verifica-se que no caso da cafeína a capacidade de adsorção, $q_{m}$, é significativamente superior quando comparado o mesmo parâmetro no caso da adsorção do corante AM-9, o que está certamente relacionado com a menor dimensão da molécula de cafeína. No entanto, a constante de Langmuir, $K_{L}$, relativa ao corante AM-9 é substancialmente superior o que indica uma maior afinidade entre a molécula de corante e a superfície do carvão. A influência da dureza da água e do tratamento oxidativo do carvão ativado foi estudado na remoção do corante AM-9. Verificou-se que a maior dureza da água tem um efeito benéfico na remoção do corante, o que se traduz numa maior capacidade de adsorção, $q_{m}$. Por outro lado, após o tratamento oxidativo os parâmetros

Tabela 2 - Parâmetros da equação linearizada de Langmuir, parâmetros estatísticos de ajuste e valores de $\mathrm{pH}_{\mathrm{pzc}}$

\begin{tabular}{|l|l|c|c|c|c|c|c|}
\hline \multicolumn{1}{|c|}{ Adsorvato } & \multicolumn{1}{|c|}{$\begin{array}{c}\text { Amostra } \\
\text { Carvão }\end{array}$} & $\begin{array}{c}q_{m} \\
(\mathrm{mg} / \mathrm{g})\end{array}$ & $\begin{array}{c}K_{L}\left(\mathrm{dm}^{3} /\right. \\
\mathrm{mg})\end{array}$ & $R^{2}$ & \multicolumn{1}{c|}{$s d_{f i t}$} & $F$ & $p H_{p z c}$ \\
\hline Cafeína & Panreac & 293 & 0,025 & 0,94 & 0,032 & 77 & 6,7 \\
\hline & & & & & & & \\
\hline AM-9 & Panreac & 213 & 0,148 & 0,99 & 0,003 & 22947 & 6,7 \\
\hline AM-9 & Panreac-Ox & 93 & 0,032 & 0,92 & 0,083 & 60 & 2,8 \\
\hline AM-9 & Panreac-200 & 292 & 0,097 & 0,99 & 0,013 & 364 & - \\
\hline
\end{tabular}


parâmetros $q_{m}$ e $K_{L}$ apresentam valores mais baixos, mostrando assim que neste caso em particular, a presença de uma maior concentração de grupos oxigenados superficiais não beneficia a remoção do contaminante.

\section{CONCLUSÕES}

Esta atividade experimental permite aos estudantes de Licenciatura em Química, Engenharia Química ou áreas afins aplicar conceitos e avaliar qualitativa e quantitativamente um processo de adsorção e, simultaneamente, introduzir alguns noções sobre poluição do meio aquático e tecnologias de tratamento de efluentes. No entanto o objetivo principal da atividade é transmitir aos estudantes conhecimentos sobre (i) capacidade de remoção de um carvão ativado na presença de contaminantes com características distintas, (ii) influência da força iónica da água onde o contaminante se encontra e (iii) efeito da química superficial do carvão. A experiência proposta é versátil e, dependendo do número de estudantes e do equipamento disponível, permite estudar o comportamento de outras amostras de carvão ativado, outras moléculas de adsorvato bem como diferentes condições de dureza da água ou da química superficial do carvão.

\section{AgradeCIMENTOS}

Os autores agradecem a colaboração do Prof. Marco Ferreira, Prof. a Maria Fátima Santos e dos alunos Daniela Nunes, Vera Santos e Daniel Neves da Escola Profissional de Setúbal. Agradecem também à Prof. a Ana Paula Carvalho do CQB/FCUL pela caracterização da amostra de carvão por isotérmicas de adsorção de $\mathrm{N}_{2}$ e ao Prof. José Coelho do ISEL pelo fornecimento do corante Azul Mordente-9.

\section{REFERÊNCIAS}

[1] P. Atkins, J. de Paula, "Physical Chemistry", $8^{\mathrm{a}}$ ed., Oxford University Press, Oxford, 2006

[2] I. N. Levine, "Physical Chemistry", $5^{\text {th }}$ ed., McGraw-Hill, Boston, 2002

[3] B.L. Dunicz, J. Chem. Educ. 38 (1961) 357-358

[4] J.H. Potgieter, J. Chem. Educ. 68 (1991) 349-350

[5] L.Tribe, B.C. Barja, J. Chem. Educ. 81 (2004) 1624-1627

[6] G. Guirado, J.A. Ayllón, J. Chem. Educ. 88 (2011) 624-628

[7] C.W. Warland, J.W. Nibler, D.P. Shoemaker, "Experiments in Physical Chemistry” $8^{\text {th }}$ ed., McGraw-Hill, New York, 2009

[8] A.M. Halpern, "Experimental Physical Chemistry: a laboratory textbook”, $2^{\text {nd }}$ ed., Prentice Hall, Upper Saddle River, 1997

[9] Y.C. Sharma, U. Upadhyay, S.N. Upadhyay, Energy Fuels 23 (2009) 2983-2988

[10] A.P. Newman, A.-H. Amjad H. El-Sheikh, A.P. Newman, H. K. Al-Daffaee, S. Phull, N. Cresswell, J. Anal. Appl. Pyrolysis 71 (2004) 151-164

[11] D.N. Jadhav, A.K. Vanjara, Indian J. Chem. Technol. 11 (2004) $42-50$

[12] M.J. Glade, Nutrition 26 (2010) 932-938

[13] I.J. Buerge, T. Poiger, M.D. Muller, H.-R. Buser, Environ. Sci. Technol. 37 (2003) 691-700

[14] A.S. Mestre, S.C.R. Marques, A.P Carvalho, Ind. Eng. Chem. Res. 51 (2012) 9850-9857

[15] F. Rodríguez-Reinoso, Carbon 36 (1998) 159-175

[16] A. Martins, N. Nunes, J. Chem. Educ. 92 (2015) 143-147

[17] S.J. Greg, K.S.W. Sing, “Adsorption, Surface Area and Porosity”, $2^{\text {nd }}$ ed., Academic Press, London, 1982
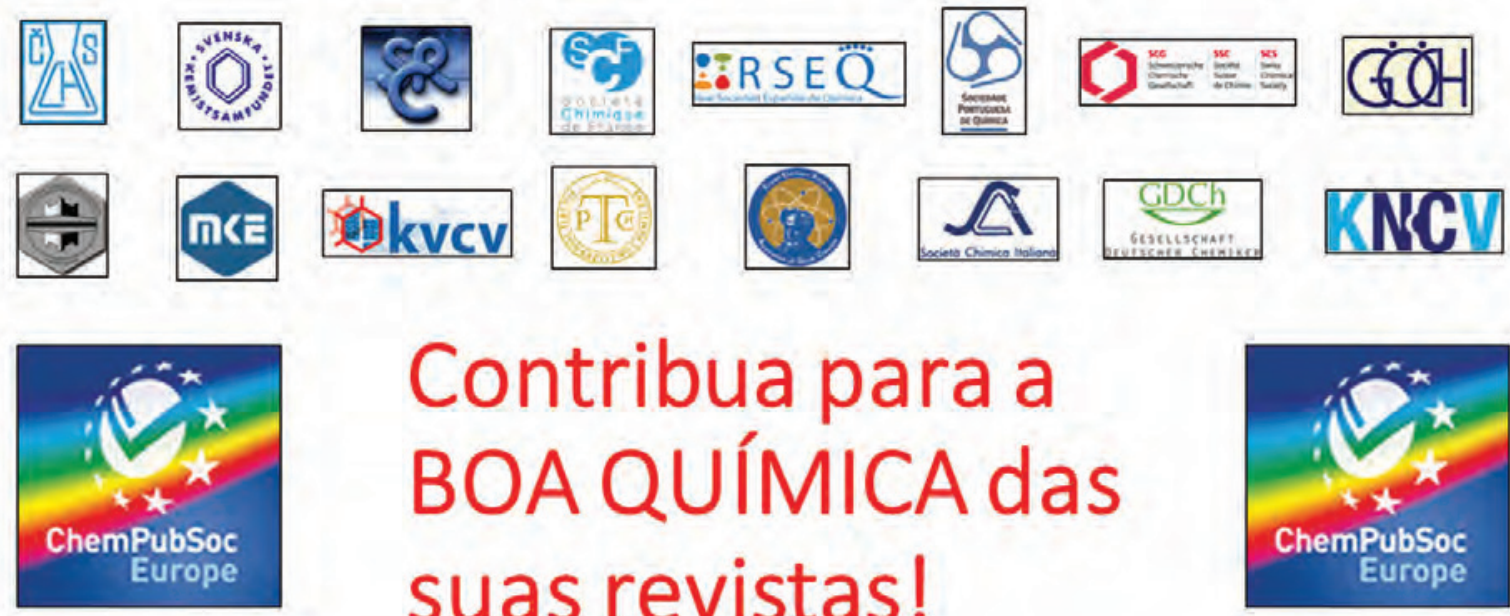

\section{Contribua para a BOA QUÍMICA das suas revistas!}
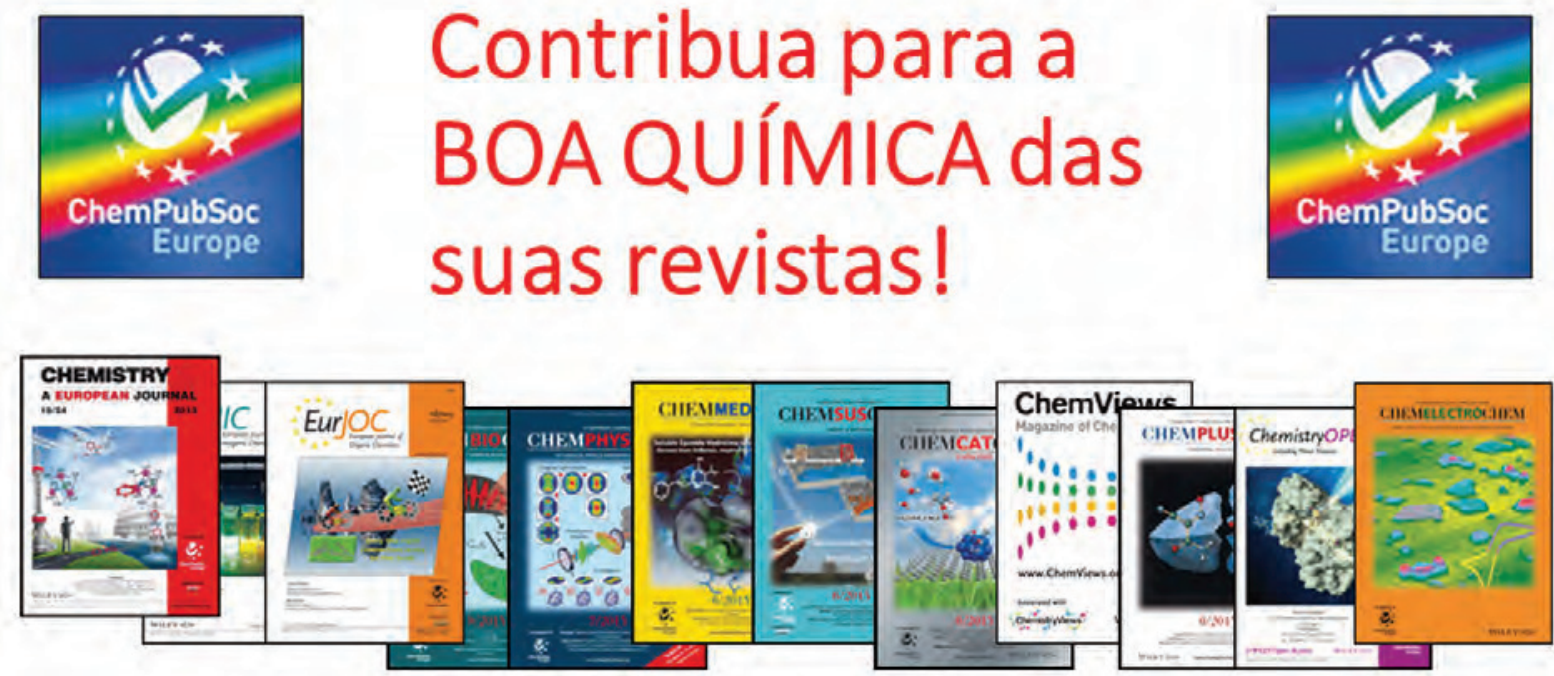